Letter to Editor

\section{The expected second wave of COVID-19}

\author{
Madiha Asghar* and Misbahud Din \\ Department of Biotechnology, Quaid-i-Azam University Islamabad, Pakistan
}

The pandemic of Coronavirus Disease (COVID-19) caused by Severe Acute Respiratory Syndrome Coronavirus-2 (SARS-CoV-2) continues to rise around the globe. As per $15^{\text {th }}$ July 2020, the World Health Organization (WHO) reported 13,119,239 confirmed COVID-19 cases along with 573,752 confirmed deaths globally [1].

Based on the past pandemic's experiences, the SARSCoV-2 can return with even more lethal force, hence it could be assumed that second wave of the pandemic could be more lethal. Epidemiologist argued that SARS-CoV-2 is a new virus and it is not clear that this pandemic will follow the pattern of previous pandemics. It has been reported that past models could be used to predict the coronavirus pattern [2]. It is believed that the first wave of the current pandemic will continue to spread with daily cases and deaths elevating and falling until the population attains herd immunity which seems unlikely without a vaccine widely available.

Over a century ago, a respiratory infection known as Spanish flu had far more devastating second wave and caused huge mass mortality [3]. The second wave had been triggered by soldiers travelling across the areas, a probable virus mutation and the states failed to impose the physical distancing measures. Moreover, public frustration was the main cause in response to mandatory use of masks in 1918 that leads to protests for Anti-Mask League in San Francisco causing 45,000 confirmed flu cases with the deaths of over 3,000 individuals.

Coronavirus spreads more easily from person to person. In summer, people are more outdoor and able to stay apart which significantly decreases transmission but in winter, indoor activities can increase the chances of virus transmission in enclosed environments. Similarly, the lockdowns have also kept people apart, therefore, the ease in lockdowns could also increase the risk of social gathering. Researchers urged that the current pandemic might last for more two to three years and could be slowdown when more than $65 \%$ of the population around the world achieve immunity [4]. They also urged that the current wave of pandemic might be followed by repeated smaller waves which are supposed to appear consistently. Similarly, the expected future waves could be geographically

\author{
More Information \\ *Address for Correspondence: Madiha Asghar, \\ Department of Biotechnology, Quaid-i-Azam \\ University, Islamabad, Pakistan, Email: \\ madihaasghar315@gmail.com; \\ misbah@bs.qau.edu.pk \\ Submitted: 21 August 2020 \\ Approved: 02 September 2020 \\ Published: 03 September 2020 \\ How to cite this article: Asghar M, Din M \\ The expected second wave of COVID-19. Int J \\ Clin Virol. 2020; 4: 109-110. \\ DOI: 10.29328/journal.ijcv.1001024 \\ Copyright: @ 2020 Asghar M, et al. This is \\ an open access article distributed under the \\ Creative Commons Attribution License, which \\ permits unrestricted use, distribution, and \\ reproduction in any medium, provided the \\ original work is properly cited. \\ W) Check for updates \\ OPEN ACCESS
}

different, and their intensity might be dependent on the local control measures. Before the end of 2020, the worst scenario of larger second wave is also expected. These predications are based on the trends that have been exhibited during 191819 pandemic of influenza virus which have resulted about 50 million deaths, and 2009-10 pandemic of H1N1 [5]. Based on previous models, the authorities must be prepared for at least 18-24 months of COVID-19 activity. With the wanes of pandemic, the SARS-CoV-2 is expected to continue circulation in the human population and synchronize to seasonal pattern decreased severity overtime, like other less pathogenic coronaviruses i.e. beta coronaviruses HKU1 and OC43 and influenza pandemics [4].

In case of the current COVID-19 pandemic, the fear of ease in restriction and ignorance of the preventive measure by the public could make the second wave more disastrous. Similarly, coepidemics of infections such as dengue outbreaks could make the situations worse in developed and underdeveloped countries [5]. Scientists have concerns that if the protective measures such as avoiding social gathering, hand washing, wearing masks, and screening of the symptoms are not sustained, larger number of cases could occur which will again lead to reimposing self-quarantine polices. Some experts are hoping to gaze into the future by observing the behavior of previous respiratory illnesses. For example, influenza and common cold seem to be linked to the cool weather during the colder months. The low humidity in the colder weather causes the virus to spread better. COVID-19 will be the part of future but whether the second wave will be a devastating 
tsunami or just a ripple may hinge on continued social distancing, masking, widespread testing, hospital preparation and vaccine development.

\section{References}

1. World Health Organization.2020. https://www.who.int/news-room/ factsheets/detail/dengue-and-severe-dengue

2. Albery GF, Eskew EA, Ross N, Olival KJ. Predicting the globa mammalian viral sharing network using phylogeography. Nature Commun. 2020; 11: 1-9.

PubMed: https://www.nature.com/articles/s41467-020-16153-4
3. Saunders-Hastings PR, Krewski D. Reviewing the history of pandemic influenza: understanding patterns of emergence and transmission Pathogens. 2016: 5: 66.

PubMed: https://pubmed.ncbi.nlm.nih.gov/27929449/

4. Kissler SM, Tedijanto C, Goldstein E, Grad YH, Lipsitch M. Projecting the transmission dynamics of SARS-CoV-2 through the postpandemic period. Science. 2020; 368: 860-868.

PubMed: https://pubmed.ncbi.nlm.nih.gov/32291278/

5. Din M, Asghar M, Ali M. COVID19 and dengue coepidemics: A double trouble for overburdened health systems in developing countries. J Med Virol. 2020.

PubMed: https://www.ncbi.nlm.nih.gov/pmc/articles/PMC7404527/ 